\section{International Scientific Journal Theoretical \& Applied Science}

\author{
p-ISSN: 2308-4944 (print) e-ISSN: 2409-0085 (online) \\ Year: 2015 Issue: 10 Volume: 30 \\ Published: $30.10 .2015 \quad \underline{\text { http://T-Science.org }}$
}

Svetlana Valeryevna Fedorova

Candidate of Technical Sciences, associate professor of the Department of World economy, Irkutsk national - research technical university, Russia $\underline{\text { fsta@istu.irk.ru }}$

SECTION 12. Geology. Anthropology. Archeology.

\title{
RESEARCH INFLUENCE OF THE CHEMICAL COMPOSITION OF MICAS ON THEIR ELECTRIC PROPERTIES AND CREATION SLYUDOKOMPOZITOV
}

\begin{abstract}
The problem of creation of reliable heating devices priobrektat the big importance for a national economy. The heating devices existing now are used, generally for the household purposes. They are difficult in production, power-intensive, not of a priksposoblena for use in hostile and damp environment. The Slyudokeramichesky electric heating element (slyudokompozit), possesses high chemical resistance, a tepkloprovodnost, moisture resistance, durability, is reliable in work, electrically safe in operation.

Key words: Slyudokeramichesky electric heating element, chemical resistance.

Language: Russian

Citation: Fedorova SV (2015) RESEARCH INFLUENCE OF THE CHEMICAL COMPOSITION OF MICAS ON THEIR ELECTRIC PROPERTIES AND CREATION SLYUDOKOMPOZITOV. ISJ Theoretical \& Applied Science 10 (30): 28-31.

Soi: http://s-o-i.org/1.1/TAS-10-30-8 Doi: crossef http://dx.doi.org/10.15863/TAS.2015.10.30.8

\section{ИССЛЕДОВАНИЕ ВЛИЯНИЕ ХИМИЧЕСКОГО СОСТАВА СЛЮД НА ИХ ЭЛЕКТРИЧЕСКИЕ СВОЙСТВА И СОЗДАНИЕ СЛЮДОКОМПОЗИТОВ}

Аннотация: Проблема создания надежных нагревательных устройств приобретает большую значимость для народного хозяйства. Существующие в настоящее время нагревательные приборы применяются, в основном, для бытовых целей. Они сложны в изготовлении, энергоемки, не приспособлень для использования в агрессивных и влажных средах. Слюдокерамический электронагревательный элемент (слюдокомпозит), обладает высокой химической стойкостью, теплопроводностью, влагостойкостью, прочностью, надежен в работе, электробезопасен в эксплуатации.
\end{abstract}

Ключевые слова: Слюдокерамический электронагревательный элемент, химическая стойкость.

Слюда - один из распространенных породообразующих минералов, который используют для создания слюдокомпозитов. Наибольший практический интерес представляют электротехнические слюды, которые являются объектом нашего исследования. Нами был изучен химический состав флогопитов различных месторождения Алданаского слюдоносного района: Эльконка, Тимптон, а также Слюдянского, Ковдорского и Арябиловского месторождений.

Анализ показал, что во всех слюдах содержания оксидов $\mathrm{SiO}_{2}$ и $\mathrm{Al}_{2} \mathrm{O}_{3}$ примерно равны по своему процентному соотношению и колеблются для $\mathrm{SiO}_{2}$ от 37,79 до $39,83 \%$, а для $\mathrm{Al}_{2} \mathrm{O}_{3}$ - от 14,36 до $17,80 \%$. Наличие в слюдах остальных химических компонентов очень сильно варьируется, что, несомненно, влияет на их свойства.

Основываясь на изучении работ, проводимых Е.К. Лашевым, П.В. Калининым, Г.П. Федосеевым [1,с.324], можно выделить эти влияния. Окраска флогопита связана с наличием в нем железа и титана. Наиболее светлые слюды приурочены к породам, бедным железом, темные разновидности слюды встречаются в породах с высоким содержанием железа и титана. Железо находится в виде: гематит - $\mathrm{Fe}_{2} \mathrm{O}_{3}$, магнетит $\mathrm{Fe} 0 * \mathrm{Fe}_{2} \mathrm{O}_{3}$. Кристаллы представляют собой пластины от коричнево-красного до черного цветов.

При изучении работ, проводимых Е.К. Лашевым, выяснилось, что тангенс диэлектрических потерь у флогопитов 
значительно выше, чем у мусковитов, и составляет у темных флогопитов от 0,002 до 0,07 в зависимости от содержания трехвалентного и двухвалентного железа. Значит, у слюд с большим содержанием этих оксидов электроизоляционные свойства слюды снижаются, поэтому в электротехнической промышленности необходимо использовать слюды с наименьшим содержанием железа. В таблице 1 приведен химический состав флогопитов по исследуемым компонентам.

Химический состав флогопитов по оксидам железа.

Таблица 1

\begin{tabular}{|c|c|c|c|c|c|}
\hline Оксиды, \% & \multicolumn{5}{|c|}{ Месторождения } \\
\hline & Слюдянка & Эльконка & Тимптон & Ковдор & Арябиловское \\
\hline $\mathrm{Fe}_{2} \mathrm{O}_{3}$ & $0,13-1,67$ & $0,93-3,41$ & $2,04-2,91$ & $3,07-3,41$ & $2,03-2,14$ \\
\hline $\mathrm{Fe} 0$ & $1,28-5,2$ & $3,86-3,96$ & 1,73 & $3,22-3,67$ & $1,26-1,77$ \\
\hline
\end{tabular}

Из результатов исследований и сравнения флогопитов между собой, можно выявить, что этому требованию соответствуют флогопиты месторождений Слюдянка и Эльконка.

П.В. Калининым, Г.П. Федосеевым [2,с.126] проводилось изучение химических свойств слюды. Компоненты, входящие в состав флогопитов, определяют и структуру оверхностного слоя. Вследствие наличия ионов калия в виде $\mathrm{K}_{2} \mathrm{O}$ и ионов натрия в виде $\mathrm{Na}_{2} \mathrm{O}$ в больших количествах, слюда способна адсорбировать влагу, так как эти компоненты являются активными по отношению к воде. Влага, находясь на поверхности, начинает химически взаимодействовать с щелочными окислами и гидратизировать их.

Реакция гидролиза будет идти по уравнениям:

$$
\begin{aligned}
& \mathrm{Na}_{2} 0 * \mathrm{SiO}_{2}+\mathrm{H}_{2} \mathrm{O}=2 \mathrm{NaOH}+\mathrm{SiO}_{2}, \\
& \mathrm{~K}_{2} \mathrm{O}+\mathrm{H}_{2} \mathrm{O}=2 \mathrm{KOH}+\mathrm{SiO}_{2} .
\end{aligned}
$$

Образовавшиеся едкие щелочи $\mathrm{NaOH}$ и КОН могут частично растворяться в конденсированной на поверхности влаге, частью взаимодействовать с углекислым газом окружающего пространства и переходить в карбонаты

$$
\begin{aligned}
& 2 \mathrm{NaOH}+\mathrm{CO}_{2}=\mathrm{Na}_{2} \mathrm{CO}_{3}+\mathrm{H}_{2} \mathrm{O} \\
& 2 \mathrm{KOH}+\mathrm{CO}_{2}=\mathrm{K}_{2} \mathrm{CO}_{3}+\mathrm{H}_{2} \mathrm{O}
\end{aligned}
$$

Слюды, содержащие $\mathrm{Na}_{2} \mathrm{O}$ и $\mathrm{K}_{2} \mathrm{O}$ в больших количествах, будут менее приемлемы в электроизоляционной промышленности. В таблице 2 представлен химический состав слюды, содержащей ионы калия и натрия.

По результатам экспериментов и сопоставления флогопитов между собой, можно предположить, что наиболее приемлемой является слюда месторождений Арябиловское и Тимптон, так как эти флогопиты содержат в своем составе меньшее количество щелочных компонентов.

Таблица 2

Химический состав слюды.

\begin{tabular}{|c|c|c|c|c|c|}
\hline Оксиды, \% & \multicolumn{5}{|c|}{ Месторождения } \\
\hline & Слюдянка & Эльконка & Тимптон & Ковдор & Арябиловское \\
\hline $\mathrm{Na}_{2} \mathrm{O}$ & $0,27-1,02$ & $0,65-0,75$ & $0,45-0,98$ & $0,54-0,6$ & $0,29-0,54$ \\
\hline $\mathrm{K}_{2} \mathrm{O}$ & $9,38-10,42$ & $9,68-10,55$ & $9,23-10,32$ & $9,14-9,51$ & $10,2-10,21$ \\
\hline
\end{tabular}

В работах К.И. Волкова, П.Н. Загибалова, Н.С. Мецика [1,c.324] указывается, что флогопит, в кристаллической структуре которого вместо гидроксилов (ОН) находятся атомы фтора, обладает высокой термостойкостью при сохранении диэлектрических свойств. Содержания фтора в слюдах различных месторождений, по результатам исследования, составляют: Слюдянка - 2,02-2,80\%; Эльконка $1,30-3,90 ; \%$ Тимптон - 2,0-4,4\%; Ковдор- 0,22$0,34 \%$; Арябиловское - 3,5-3,7\%.

Самое большое наличие фтора было обнаружено в слюдах месторождений Эльконка и
Арябиловское. Эти флогопиты можно рекомендовать для производства электроизоляционных изделий. Результаты наших исследований позволяют утверждать, что месторождения флогопита Эльконка и Арябиловское по электрическим и химическим свойствам наиболее выгодно использовать в изготовлении изделий электроизоляции.

Слюдокерамические материалы (слюдокомпозиты) являются сравнительно новыми, они получили широкое распространение в различных областях народного хозяйства. Обладают высокой электрической прочностью, 
низкими диэлектрическими потерями, инертны к действию воды, кислот, спиртов, растворителей и масел. Молотая слюда - полуфабрикат для производства слюдекерамических материалов (СКЭНов). В зависимости от требований, предъявляемых к материалам, используют ее различные виды. В качестве второго компонента для изготовления СКЭНов употребляется алюмоборосиликатное стекло № 203. Применяемое в настоящее время стекло № 203 является дорогостоящим компонентом. Значительный интерес представляет разработка связующего на базе боя стекольных заводов. Для снижения температуры размягчения стеклобоя были использованы легкоплавкие добавки.

Термические процессы в смесях слюда стекло в соотношениях 40:60 исследовались с помощью термографии. Термические превращения наблюдали на дериватографе системы Ф. Паулик, И. Паулик, Л. Эрдеи фирмы "МОМ" (Венгрия). Нагрев производился в керамических тиглях. Навеска слюды со стеклом составляла 500 мг, 300 мг приходилось на слюду. Соотношение $\quad 40 \%$ стекла и $\quad 60 \%$ слюды выдерживается по технологии изготовления микалекса [3,с.16-32] .

Плавни добавлялись за счет стекла. Потеря массы в слюде обусловлена, главным образом, тремя процессами: выделением адсорбированных газов (главным образом, паров воды), многоступенчатой дегидратацией и дегидроксилацией (выделением структурных $\mathrm{OH}$ групп). В мусковите десорбция протекает в три этапа. В присутствии стекла в смеси со слюдой нами наблюдались термоэффекты, соответствующие термоэффектам слюды.

При введении плавней $\mathrm{KNO}_{3}, \mathrm{~K}_{2} \mathrm{SO}_{3}$, $\mathrm{Na}_{2} \mathrm{SiF}_{6}$ спекание отсутствует, что подтверждается наличием неспекшейся массы. Очевидно, введение плавней, не снизило температуру размягчения стеклобоя. Высокотемпературный эндоэффект, соответствующий дегидроксилации, в этих случаях наблюдается при температурах близких к температурам этого эффекта в чистой слюде.

Исследовались смеси слюды и стеклобоя с плавнем. В области температур $800-940^{\circ} \mathrm{C}$ отмечался экзоэффект, а не эндо-. Температура дегидроксилации слюды сместилась в сторону понижения. При введении 2\% $\mathrm{CaF}_{2}$ температура начала экзоэффекта составляла $580^{\circ} \mathrm{C}$, а при введении $5 \% \mathrm{CaF}_{2}-420^{\circ} \mathrm{C}$. Эффект зависит от количества добавки плавня $\mathrm{CaF}_{2}$. Наблюдаются более существенный температурный сдвиг начала процесса в сторону понижения и его большая интенсификация при большем количестве.

Из результатов эксперимента видно, что процесс взаимодействия происходит в зоне дегидроксилации. Этот факт подтверждается наличием экзоэффекта при температуре 740$1000^{\circ} \mathrm{C}$. По окончании съемки в тигле образовался стекловидный спек, что говорит о формировании прочной композиции и возможности использования стеклобоя в качестве матрицы.

Проводился расчет энергии активации с помощью расчета кинетических констант методом Хоровитца - Мецгера. С увеличением количества плавня энергия активации уменьшилась: при введении она составляла наименьшее значение. При повышенной добавке плавня (до 5\%) энергия активации понижалась, т.е. возрастала вероятность спекания слюды со стеклом. Значения энергии активации представлены в таблице.

Таблица 3

Результаты расчета энергии активации.

\begin{tabular}{|c|c|c|}
\hline Минерал & Содержание, \% & Е, кдж \\
\hline $\mathrm{KNO}_{3}$ & 2 & 207,3 \\
\hline $\mathrm{KNO}_{3}$ & 5 & 298 \\
\hline $\mathrm{K}_{2} \mathrm{SO}_{3}$ & 2 & 202 \\
\hline $\mathrm{K}_{2} \mathrm{SO}_{3}$ & 5 & 186 \\
\hline $\mathrm{Na}_{2} \mathrm{SiF}_{6}$ & 2 & 138 \\
\hline $\mathrm{Na}_{2} \mathrm{SiF}_{6}$ & 5 & 133 \\
\hline $\mathrm{CaF}_{2}$ & 2 & \\
\hline $\mathrm{CaF}_{2}$ & 5 & \\
\hline
\end{tabular}




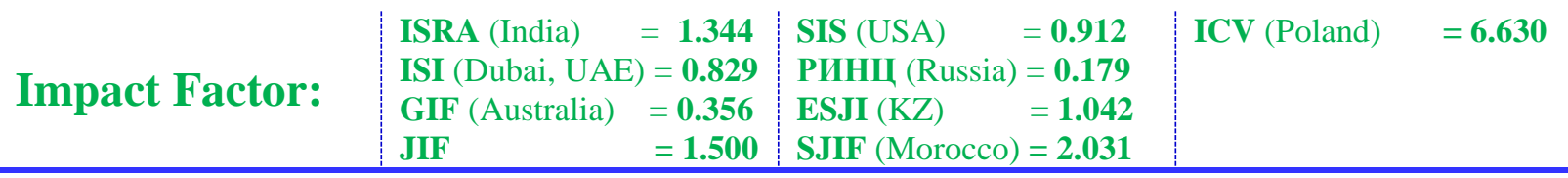

Смещение в сторону более низких температур процессов дегидроксилации и снижение энергии активации можно объяснить растворением частичек слюды в стекле. Из результатов исследований следует, что стекло с добавлением плавня $\mathrm{CaF}_{2}$ нужно рекомендовать для изготовления корпусов слюдокерамических электронагревателей.

\section{References:}

1. Volkov KI, Zagibalov PN, Mecik MS (1971) Svojstva, dobycha i pererabotka sljudy. Irkutsk, 1971. pp. 324.

2. (1967) Trudy instituta Giproniinemetallorud. L., 1967. pp. 126.

3. Suloev AI, Samojlova EI (1940) Izuchenie vkljuchenij $\mathrm{v}$ sljudah $\mathrm{v}$ svjazi $\mathrm{s}$ ih kachestvennoj harakteristikoj. - Moscow, L., 1940. pp. 16-32.

4. Shishelova TI, Chilikanova DV, Borzov VG, Bajborodin BA (1986) Mikaleks. - Irkutsk, 1986. - pp. 112.

5. Veksler S, Ozhigov VN, Mecik MS (1973) Issledovanie termostojkosti kristallov sljudy // Issledovanie $\mathrm{v}$ oblasti fiziki tverdogo tela. Vyp. I. - Irkutsk, 1973. - pp. 164-168.

6. Bajborodin BA, Plahova EN (1987) Issledovanie formy i krupnosti sljudjanogo syr'ja, primenjaemogo pri proizvodstve sljudokeramicheskih jelektronagrevatel'nyh jelementov //Obogashhenie rud. - Irkutsk, 1987. - pp. 69-74.

7. Bajborodin BA, Shishelova TI, Chilikanova LV (1979) Izuchenie vlijanija izmel'chenija sljudy na fizicheskie svojstva mikaleksa //Tez. dokl. obl. nauchno-tehn.konf.,posv. Dnju radio. Novosibirsk, apr. 1979 g. - Novosibirsk, 1979. pp. 141-142.

8. Bajborodin BA (1984) Teorija obogashhenija i pererabotki melkoraz $\neg$ mernogo sljudjanogo syr'ja: Dis. d-ra tehn.nauk. - Irkutsk, 1984. pp.314.

9. (1982) Algoritmy kontrolja i upravlenija tehnologicheskimi processa mi v nemetallurgicheskoj promyshlennosti /VNII nerud.stroitel'stva materialov gidromehanizacii. - Tol'jatti, 1982. -pp. 92.

10. Andreev SE (1962) Soderzhanie krupnogo klassa $\mathrm{V}$ mel'nice opredeljaet ee proizvoditel'nost' //Obogashhenie rud. - 1962. № 2. - pp.3-6. 